\title{
Optic capture pars plana lensectomy
}

This article was published in the following Dove Press journal:

Clinical Ophthalmology

30 October 2012

Number of times this article has been viewed

\section{Joo Eun Lee}

Department of Ophthalmology, Inje University College of Medicine, Busan, South Korea
Correspondence: Joo Eun Lee

Department of Ophthalmology, Haeundae Paik Hospital, Inje University

College of Medicine, I 435 Jwa-dong,

Haeundae-gu, Busan 6|2-03|,

South Korea

$\mathrm{Tel}+82517972310$

Fax +82 5I 7972321

Email jooeun2@paik.ac.kr
Objective: To describe an optic capture pars plana lensectomy technique.

Methods: After core vitrectomy, pars plana lensectomy is performed with preservation of the anterior capsule. Capsulorhexis is performed on the preserved anterior capsule through a $2.8 \mathrm{~mm}$ clear corneal incision. An intraocular lens (IOL) is placed in the ciliary sulcus, and then the optic of the IOL is pushed back to the vitreous cavity so that the optic is captured by the surrounding capsulorhexis margin.

Results: The captured IOL-capsule diaphragm remained stable during air-fluid exchange and prevented air prolapse to the anterior chamber. IOL stability and a clear visual axis were preserved during the follow-up period.

Conclusion: With this modified pars plana lensectomy technique, stable IOL position and clear visual axis can be maintained when a pars plana approach is needed during combined cataract and vitreoretinal surgery.

Keywords: lensectomy, optic capture, pars plana lensectomy, vitrectomy

\section{Introduction}

Phacoemulsification has become a standard method in modern combined cataract and vitreoretinal surgery due to advances in equipment and techniques. Pars plana lensectomy, however, could be a better approach in certain settings, such as existing posterior polar cataract, ${ }^{1}$ pediatric patients, ${ }^{2}$ or traumatic cataract in which the posterior capsule is already damaged. ${ }^{3}$

Major disadvantages of pars plana lensectomy as compared to phacoemulsification include: compromised capsular bag due to the removal of the posterior capsule during lensectomy; subsequent less stable intraocular lens (IOL) position in the ciliary sulcus, with an increased risk of tilting or dislocation of the IOL; risk of air/silicone oil prolapse to the anterior chamber if a large anterior capsulotomy was made; and development of opacification of the remaining anterior capsule, if the anterior capsule was preserved.

The author introduces an optic capture pars plana lensectomy technique in which after an anterior capsule preserving lensectomy - capsulorhexis is made on the remaining anterior capsule followed by optic capture of an IOL into the capsulorhexis to resolve the shortcomings of conventional pars plana lensectomy.

\section{Patient and methods}

The patient was a 60-year-old woman with diabetic vitreous hemorrhage and tractional retinal detachment combined with thick posterior polar cataract. 


\section{Surgical technique}

\section{Anterior capsule-preserving pars plana lensectomy}

A standard preparation for 20 -gauge pars plana vitrectomy was made, including conjunctival peritomy and three sclerotomies. After a core vitrectomy was performed, the nucleus of the lens was initially crushed with a microvitreoretinal blade and a 20-gauge needle introduced through a superotemporal and superonasal sclerotomies, respectively (Figure 1A). The nucleus was then removed with a fragmatome and a vitreous cutter through the pars plana, and cortical cleaning was performed using the active vacuum of the vitreous cutter (Figure 1B). The posterior capsule was removed during the procedure, but care was taken to preserve the anterior capsule.

\section{Capsulorhexis on the remaining anterior capsule} and capture of the optic of an intraocular lens to the capsulorhexis

After completion of the vitrectomy, viscoelastic material was introduced into the anterior chamber through a side-port stab

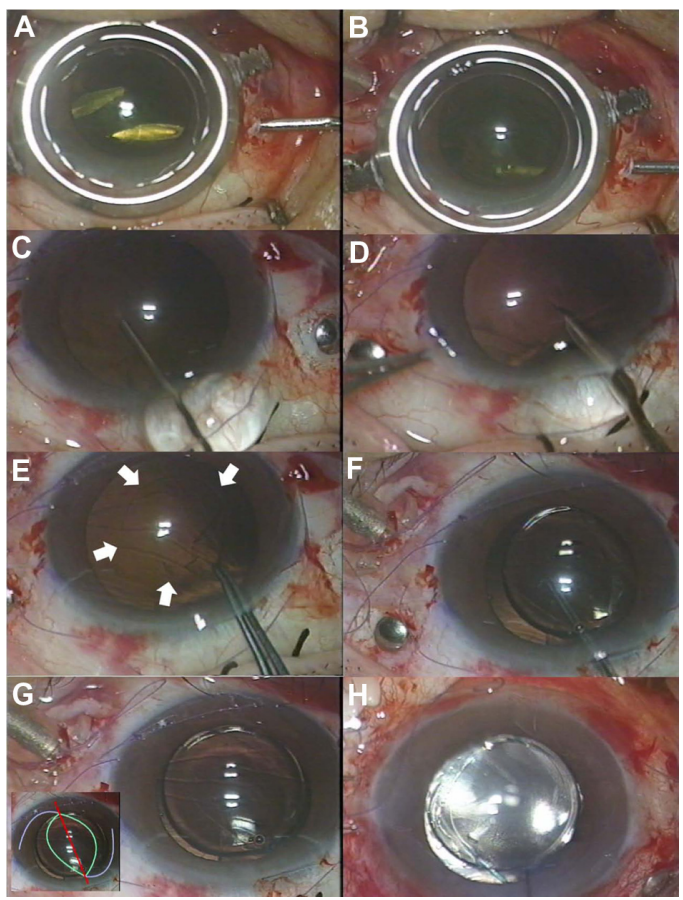

Figure I (A-H) Intraoperative photographs. (A) Lens nucleus is crushed using a microvitreoretinal blade and a 20 -gauge needle. (B) Lens material is removed using vitreous cutter. Care is taken not to damage the anterior capsule. (C) Viscoelastic material is injected into the anterior chamber through a $2.8 \mathrm{~mm}$ superior clear corneal incision. (D) A puncture is made on the remaining anterior capsule using a bent needle. (E) Continuous curvilinear capsulorhexis is being done on the anterior capsule. White arrows indicate the margin of the capsulorhexis being made. (F) An IOL is placed in the ciliary sulcus initially, then the IOL optic is captured through the capsulorhexis. (G) The successfully captured IOL makes an oval capsulorhexis margin. Inset: A graphic illustration of the shape of the capsulorhexis margin (green line) and the position of the haptics (purple lines). (H) The captured IOL-capsule diaphragm maintains stability during fluid-air exchange.

Abbreviation: IOL, intraocular lens. incision, and a superior clear corneal incision of $2.8 \mathrm{~mm}$ in length was made. After complete replacement of the aqueous humor with viscoelastic material (Figure 1C), a small puncture was made on the preserved anterior capsule with a bent needle (Figure 1D). Then capsulorhexis was performed using capsulorhexis forceps (Figure 1E).

After a foldable IOL was inserted into the ciliary sulcus through the corneal incision, one side of the optic was pushed back into the vitreous cavity with a Sinskey hook and then the other side of the optic was pressed in the same manner, $90^{\circ}$ from the haptic-optic junction (Figure 1F).

\section{Results \\ Intraoperative findings}

The successfully captured optic made an oval capsular configuration (Figure 1G). No difficulty was encountered in viewing the fundus through the captured optic. Even after fluid-air exchange, the capsule-IOL diaphragm was stable enough to prevent air in the vitreous cavity from migrating to the anterior chamber (Figure 1H). Additional procedures such as endolaser photocoagulation were able to be performed as usual.

\section{Postoperative findings}

Even though the patient maintained a facedown position for 2 weeks postoperatively, the captured IOL-capsular diaphragm remained stable. Tilting or dislocation of the IOL did not occur during the 12-month follow-up (Figure 2).

\section{Discussion}

Traditional pars plana lensectomy involves removing both the anterior and posterior capsule along with the crystalline lens to prevent later development of anterior capsular opacity. An anterior chamber IOL or scleral sutured posterior chamber

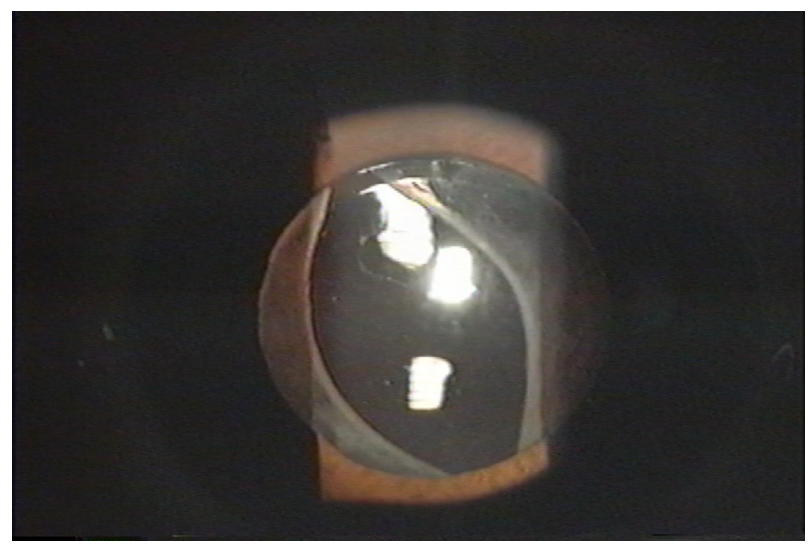

Figure 2 Slit-lamp photograph at 12 months postoperatively. 
IOL is then used. An alternative approach was to save the anterior capsule during the lensectomy followed by placing an IOL in the ciliary sulcus. An anterior capsulotomy, either by vitreous cutter or diathermy, was then made at the center of the anterior capsule to prevent anterior capsular opacification in the visual axis. ${ }^{1,2}$ By creating a capsulotomy, however, another concern is raised regarding the breakage of the stable capsular barrier. This could be especially problematic during air-fluid exchange in combined cataract and vitreous surgery, since the IOL can be subluxated by the air pressure in the vitreous cavity and the air can prolapse to the anterior chamber, ${ }^{4}$ increasing the risk of corneal endothelial cell loss. ${ }^{5}$ Some surgeons prefer to insert an IOL in a secondary operation, when fluid-air exchange or silicone oil injection is needed. ${ }^{4}$ The risk of neovascular glaucoma could also increase by free diffusion of vascular growth factors from the ischemic retina to the anterior chamber in ischemic retinal diseases, such as diabetic retinopathy.

Preservation of the anterior capsule after the lensectomy could have merits in this regard. Pars plana vitrectomy combined with pars plana lensectomy with anterior capsular preservation can facilitate sufficient removal of anterior and peripheral vitreous, allow sufficient application of endolaser photocoagulation, and prevent acute increase of vascular endothelial growth factor and inflammatory cytokine production postoperatively. ${ }^{6}$

Another option is to polish the posterior surface of the anterior capsule in the visual axis to remove as many endothelial cells as possible, using either the vacuum of the vitreous cutter or polishing instruments. ${ }^{4}$ Still, concerns exist regarding tilting or decentration of the IOL, due to the less stable location in the ciliary sulcus than in the capsular bag.

The modified technique described here can solve all these problems. The captured IOL in the capsulorhexis can work like an IOL in the capsular bag, keeping a tight seal of the lens-iris diaphragm intraoperatively and postoperatively, and reduces concerns about dislocation or subluxation of the IOL and capsular opacity in the visual axis.

The optic-capture technique was originally used in pediatric cataract surgeries on the posterior capsule to preserve a clear visual axis. ${ }^{7}$ Numerous variations of this technique have been reported so far. ${ }^{8-12}$ Likewise, performing a capsulorhexis on the remaining anterior capsule after all the lens material has been removed could be done in the same fashion as during conventional phacoemulsification. The size of the capsulorhexis is ideal to achieve a secure capture if it is $1-2 \mathrm{~mm}$ smaller than the IOL optic. ${ }^{13}$
In summary, in a situation when pars plana lensectomy is needed, anterior capsule-preserving pars plana lensectomy followed by capsulorhexis and optic capture on the preserved capsule could be a useful option. This technique offers maintenance of stable IOL position and a clear visual axis. Long-term follow-up in more patients will be needed to address possible complications related to this technique and long-term outcomes.

\section{Disclosure}

The author has no financial interest related to the article.

\section{References}

1. Ghosh YK, Kirkby GR. Posterior polar cataract surgery - a posterior segment approach. Eye (Lond). 2008;22(6):844-848.

2. Miller DM, Murray TG, Cicciarelli NL, Capo H, Markoe AM. Pars plana lensectomy and intraocular lens implantation in pediatric radiationinduced cataracts in retinoblastoma. Ophthalmology. 2005;112(9): $1620-1624$.

3. Yasukawa T, Kita M, Honda Y. Traumatic cataract with a ruptured posterior capsule from a nonpenetrating ocular injury. J Cataract Refract Surg. 1998;24(6):868-869.

4. MacCumber MW, Packo KH, Civantos JM, Greenberg JB. Preservation of anterior capsule during vitrectomy and lensectomy for retinal detachment with proliferative vitreoretinopathy. Ophthalmology. 2002; 109(2):329-333.

5. Mitamura Y, Yamamoto S, Yamazaki S. Corneal endothelial cell loss in eyes undergoing lensectomy with and without anterior lens capsule removal combined with pars plana vitrectomy and gas tamponade. Retina. 2000;20(1):59-62.

6. Kinoshita N, Ota A, Toyoda F, Yamagami H, Kakehashi A. Surgical results of pars plana vitrectomy combined with pars plana lensectomy with anterior capsule preservation, endophotocoagulation, and silicon oil tamponade for neovascular glaucoma. Clin Ophthalmol. 2011;5: 1777-1781.

7. Gimbel HV, DeBroff BM. Posterior capsulorhexis with optic capture: maintaining a clear visual axis after pediatric cataract surgery. J Cataract Refract Surg. 1994;20(6):658-664.

8. Menapace R. Posterior capsulorhexis combined with optic buttonholing: an alternative to standard in-the-bag implantation of sharp-edged intraocular lenses? A critical analysis of 1000 consecutive cases. Graefes Arch Clin Exp Ophthalmol. 2008;246(6):787-801.

9. Jones JJ, Oetting TA, Rogers GM, Jin GJ. Reverse optic capture of the single-piece acrylic intraocular lens in eyes with posterior capsule rupture. Ophthalmic Surg Lasers Imaging. Epub September 6, 2012.

10. Lee JE, Ahn JH, Kim WS, Jea SY. Optic capture in the anterior capsulorhexis during combined cataract and vitreoretinal surgery. J Cataract Refract Surg. 2010;36(9):1449-1452.

11. Vasavada AR, Praveen MR, Tassignon MJ, et al. Posterior capsule management in congenital cataract surgery. J Cataract Refract Surg. 2011;37(1):173-193.

12. Tassignon MJ, De Veuster I, Godts D, Kosec D, Van den Dooren K, Gobin L. Bag-in-the-lens intraocular lens implantation in the pediatric eye. J Cataract Refract Surg. 2007;33(4):611-617.

13. Gimbel HV, DeBroff BM. Intraocular lens optic capture. J Cataract Refract Surg. 2004;30(1):200-206. 


\section{Publish your work in this journal}

Clinical Ophthalmology is an international, peer-reviewed journal covering all subspecialties within ophthalmology. Key topics include: Optometry; Visual science; Pharmacology and drug therapy in eye diseases; Basic Sciences; Primary and Secondary eye care; Patient Safety and Quality of Care Improvements. This journal is indexed on
PubMed Central and CAS, and is the official journal of The Society of Clinical Ophthalmology (SCO). The manuscript management system is completely online and includes a very quick and fair peer-review system, which is all easy to use. Visit http://www.dovepress.com/ testimonials.php to read real quotes from published authors. 